\title{
Natural orifice translumenal endoscopic surgery (NOTES): creation of a gastric valve for safe and effective transgastric surgery in humans
}

\author{
Michael B. Ujiki · Danny V. Martinec · \\ Tayyab S. Diwan - Peter M. Denk • \\ Christy M. Dunst $\cdot$ Lee L. Swanström
}

Received: 12 February 2009/Accepted: 20 April 2009/Published online: 17 June 2009

(C) Springer Science+Business Media, LLC 2009

\begin{abstract}
Introduction NOTES has become a clinical reality. There remain, however, many challenges that need to be addressed in order to refine the technique. One of the most feared potential complications of transgastric surgery is a leak from the port of entry into the peritoneum. When withdrawing the endoscope into the gastric lumen it is difficult to make a secure closure due to the loss of pneumogastrium. We present a novel and safe technique for creating a gastrotomy developed in our animal laboratory and applied in all of our human NOTES cholecystectomies. Methods Using an aggressive grasping and needledelivery device, full-thickness bites create an imbricated ridge of tissue that acts as a valve, allowing visualization while maintaining pneumogastrium when the endoscope is withdrawn from the peritoneum into the lumen. At closure, full-thickness serosa-to-serosa approximation is easily achieved due to excellent visualization.
\end{abstract}

Electronic supplementary material The online version of this article (doi:10.1007/s00464-009-0547-7) contains supplementary material, which is available to authorized users.

M. B. Ujiki · D. V. Martinec $(\bowtie) \cdot$ T. S. Diwan ·

P. M. Denk - C. M. Dunst - L. L. Swanström

Minimally Invasive Surgery Program, Legacy Health System,

1040 NW 22nd Ave. Suite 560, Portland, OR 97210, USA

e-mail: DannyMartinec@gmail.com
Results With this technique we have been able to accomplish consistent results in ten pig models. In our series of five patients who have undergone NOTES transgastric cholecystectomy, there have been no leaks to date using the same technique. Video footage presents this technique performed on humans.

Conclusions Creation of a gastric valve during transgastric surgery has proved to be a safe approach. This technique allows maintenance of insufflation and visualization during the procedure and provides a feasible and safe means of closure at the end of the procedure.

Keywords NOTES - Transgastric - Gastrotomy closure · Cholecystectomy · Endoscopic technology $\cdot$ Surgery 